\title{
ОБ ОДНОМ ТИПЕ НОЖЕН РУБЕЖА ЭР В УРАЛО-ПОВОЛЖЬЕ
}

\author{
(C) 2020 г. В.В. Овсянников
}

В статье анализируется обнаруженные в ходе исследований Шиповского курганно-грунтового могильника в 2006-2008 гг. два погребения, содержавшие остатки ножен на боевых клинках. В них обнаружены крупные бляхи, найденные у рукояти, которые, вероятно, служили как украшение устья ножен, а также могли выполнять функцию крепления ножен к поясу. Находки таких украшений были характерны для Скифии и Бактрии, что еще раз доказывает присутствии зауральского компонента в памятниках Посурья первых веков нашей эры за счет привлечения материалов из ареала кара-абызской культуры.

Ключевые слова: археология, Южный Урал, Шиповский курганно-грунтовой могильник, Андреевский курган, погребения, мечи, кинжалы, ножны, гафурийская культура, кара-абызская культура, Скифия, Бактрия.

\section{A TYPE OF SHEATHS ON THE TURN OF EPOCHS FROM THE URAL-VOLGA REGION}

\section{V.V. Ovsyannikov}

The paper analyzes two burials revealed during studies at Shipovo barrow and ground cemetery in 20062008 containing the remains of the sheaths on battle blades. They contain large metal plates located at the handle which probably served as decorations of the sheath mouth, or were the means of fastening the sheath to a belt. The discovery of such jewelry was characteristic of Scythia and Bactria, which once again confirms the presence of the Trans-Ural component in the monuments of the Sura region in the first centuries AD due to the attraction of materials from the area of Kara-Abyz culture.

Keywords: archaeology, South Urals, Shipovo burial ground, Andreevsky barrow, burials, swords, daggers, sheaths, Gafuriyskaya culture, Kara-Abyz culture, Scythia, Bactria.

В ходе исследования автором Шиповского курганно-грунтового могильника (КГМ) в 2006-2008 гг. (Иглинский район, Башкортостан) среди воинских комплексов было выявлено два погребения, содержавших остатки ножен на боевых клинках. Оба случая объединяет наличие крупных бронзовых блях в оформлении ножен.

Первый комплекс был найден под насыпью кургана 2 III группы. В центральном воинском захоронении справа от остатков костяка лежал плохой сохранности однолезвийный клинок с сохранившейся длиной 22 см (рис. 1: 7). Клинок был уложен острием к голове погребенного. У рукояти клинка - круглая бронзовая бляха диаметром 6,5 см. В центре бляха имеет орнамент из двух вписанных друг в друга окружностей (рис. 1: 2). Бляха изготовлена из зеркала типа 5.3 (Скрипкин, 1990, c. 95). На центральной части клинка лежала круглая бляшка с прорезным орнаментом и ушком на обороте, диаметром 3,3 см (рис. 1: 6). Органических деталей кроме волокон древесины на рукояти клинка не сохранилось.

Остальной инвентарь этого воинского захоронения представлен глиняным сосудом гафурийского типа (Овсянников, 2014, рис. 4, 7), курильницей, железными удилами, наконечником копья, набором деревообрабатывающих орудий (ложкарь, тесло, долото и др.), а также остатками богато украшенного колчана, включающего две круглые умбоновидные бляхи (рис. 1: 3-4), 17 мелких бляшек, колчанный крючок (рис. 1: 1), железную пряжку с неподвижным крючком (рис. 1: 8) и 21 бронзовый наконечник стрелы (рис. 1: 9-28).

Второй воинский комплекс с ножнами происходит из кургана 24 II группы курганов Шиповского КГМ. Это впускное погребение. В нем железный однолезвийный клинок лежал у правого бедра захороненного в возрасте 20-25 лет. Сохранившаяся длина 30 см. На рукояти лежала круглая бронзовая бляха диаметром 6,7 см. В центре бляхи отверстие, в него была вставлена небольшая круглая бляшка с ушком на обороте (рис. 2: 1). Недалеко от конца клинка - круглая бронзовая бляшка с двумя отверстиями, диаметром 3,3 см (рис. 2: 6). Органических деталей ножен не сохранилось.

В комплекс также входили железные удила (рис. 2: 2), колчанный крючок (рис. 2: 3), 
бронзовая подвеска, изготовленная из фрагмента зеркала (рис. 2: 4), бронзовая бляшкараспределитель (рис. 2: 5), а также набор из 6 бронзовых и одного железного наконечников стрел (рис. 2: 8-13).

Третий воинский комплекс с подобным типом ножен известен нам из раскопок 1934 г. Старо-Киишкинского курганного могильника (Кармаскалинский район, Башкортостан). Здесь под насыпью кургана IX было вскрыто парное воинское захоронение (рис. 3). Возле правого бедра северного костяка лежал однолезвийный клинок длиной 50 см (рис. 3: 4). Конец клинка при этом слегка заходил под бедренную кость. Около рукояти клинка и острия клинка, под клинком - две бронзовые бляхи, богато украшенные орнаментом на лицевой части. На обороте имели по два ушка. Бляха у рукояти имела диаметр 5,5 см (рис. 3: 2), у острия - 4 см (рис. 3: 1). Обе бляхи лежали лицевой частью вниз. У острия клинка и между бедренными костями -5 бронзовых обоймочек с остатками ремешка (рис. 3: 3).

В этот же комплекс входит колчанный крючок (рис. 3: 17) и два набора наконечников стрел. У северного костяка -6 бронзовых и не менее 13 спекшихся железных наконечников; у южного костяка -5 бронзовых и не менее 15 спекшихся железных наконечников стрел (рис. 3: 5-18) (Дмитриев, Сальников, 1934, с. 35).

Хронологические позиции этих комплексов определяются смешанными колчанными наборами - временем смены бронзовых наконечников на железные. По раннесарматским материалам этот период датируется преимущественно III вв. до н. э. (Клепиков, Скрипкин, 2002, с. 66-67). По поводу аналогичного процесса в лесостепных культурах Предуралья в литературе давно созрело мнение о запаздывании здесь смены колчанных наборов по сравнению с ранними кочевниками (Агеев, 1992 , с. 55-56, 74-75; Иванов, 1985, с. 95). Не так давно С.Э. Зубовым и Р.Р. Саттаровым на материалах Кипчаковского I курганно-грунтового могильника период смены бронзовых наконечников железными в пьяноборских древностях определен в пределах I в до н. э. (Зубов, Саттаров, 2018, с. 213-214).

Если отвлечься от колчанных наборов, то погребения из кургана 2 Шиповского КГМ и кургана IX Старых Киишек выглядят очень близкими хронологически: практически идентичная форма умбоновидных блях и схожие по оформлению колчанные крючки. Однако колчанные наборы отличаются значительно. В старокиишкинском погребении уже преобладают железные наконечники стрел, что говорит о далеко зашедшем процессе смены дистанционного оружия. С другой стороны, шиповский набор полностью состоит из бронзовых наконечников. Возможно, на примере этих комплексов мы получаем редкую возможность предметно зафиксировать разницу в скорости смены колчанных наборов у сармат и кара-абызского населения. Абсолютную дату этой смены вряд ли можно определить по этим двум конкретным комплексам. Третий комплекс из кургана 24 Шиповского КГМ уже демонстрирует начало этого процесса и в караабызской среде. Отсутствие других хронологических реперов опять же не позволяет дать ему четкую хронологическую позицию. Однако все эти комплексы демонстрируют, что смена колчанных наборов в кара-абызской среде началась хоть и позже сармат, но незначительно, с небольшим «сдвигом» на не более чем 0,5-1 поколения. Таким образом, пока остается определить дату рассматриваемых комплексов в пределах III-II вв. до н. э.

Назначение бляшек малых форм, находившихся у окончания клинка, не вызывает сомнений - они служили для крепления нижней части ножен к бедру воина. Особенно хорошо это прослеживается в старокиишкинском комплексе. Здесь зафиксированы остатки кожаного ремешка, тянущегося от нижней малой бляхи под бедро погребенного. Ремешок сохранился благодаря украшавшим его бронзовым обоймочкам.

Крупные бляхи, находимые у рукояти, вероятнее всего, служили как украшение устья ножен, а также могли выполнять функцию крепления ножен к поясу. На основании этого предположения можно представить гипотетически, как могли выглядеть подобные ножны (рис. 4: 1-3). Для старокиишкинского комплекса можно предложить два варианта реконструкции (рис. 4: 3a-3б).

Подобный способ оформления ножен известен был в Скифии и Бактрии в V-III вв. до н. э. (рис. 4: 4-9). В большинстве случаев это, как правило, ножны всаднического типа с закреплением конца ножен на бедре всадника (рис. 4: 10-11). Остается вопрос, каким образом ножны подобного типа оказались в лесостепных комплексах Предуралья в III-II вв. до н. э. Однако его пока придется оставить открытым. Для его решения недостаточно данных. Единственно, можно определенно 
сказать, что происхождение ножен этого типа не связано с материалами раннепрохоровского (филипповского) комплекса. В последнем хорошо известны находки с боевыми клинками так называемых ворворок. Они встречаются в комплекте от 1 до 4 и также являются, в том числе, и деталями всаднической портупеи клинкового прохоровского оружия из комплексов IV в до н. э. (Клепиков, Скрипкин, 2002, с. 53-54).

В Бишунгаровско-старокиишкинской группе ранних кочевников классического прохоровского облика детали ножен или портупеи вообще не встречены вместе с боевыми клинками. Представленный нами комплекс ножен с бляхами является единственным для данной группы и явно заимствован у оседлых соседей из Шипово. Об этом в первую очередь говорит облик самих блях. Подобные бляхи широко представлены в Шиповском КГМ, и шире в кара-абызских и пьяноборских древностях. В последних они встречены не только как детали ножен, но и как детали костюма, хотя также являются мужским, а точнее воинским атрибутом.

Близкий скифскому и бактрийскому тип ножен сохраняется в Верхнем Приобье, горном Алтае и Туве (Шульга, 2008; Археология СССР, 1992, табл. 74, 21, 23, 25). Однако в зауральских лесостепных древностях (гороховские, раннесаргатские), с которыми прослеживаются тесные связи шиповского (гафурийского) населения, он пока не известен.

Интересен факт того, что описываемый тип ножен не встречается кроме Шипово в других кара-абызских некрополях, хотя короткие боевые однолезвийные клинки здесь частое явление. Однако чаще в комплекте с ними идут бронзовые наконечники ножен и небольшие портупейные пряжки. То есть наблюдается совершенно другой тип ножен. Тогда как пьяноборские памятники демонстрируют совершенно иную картину. Так, в коллективном погребении 38 могильника Уяндык I (Илишевский район, Башкортостан) у костяка III под правым предплечьем лежала умбоновидная бляха и однолезвийный боевой клинок (рис. 5: 7-11). Комплекс в данном случае дополняется 20 бронзовыми наконечниками стрел, что хронологически сближает его с шиповскими (Пшеничнюк, 1986, с. 40). Аналогичные бляхи с однолезвийным клинком встречены в погребении 5 Кырнышского могильника (Мензелинский район, Татарстан)
(Генинг, 1971, с. 137; рис. 44, 13). В погребении 11 Кипчаковского I КГМ (Илишевский район, Башкортостан) под правым предплечьем лежала круглая бляха с петлей и короткий боевой однолезвийный клинок (рис. 5: 1-2, 6). Бляха была изготовлена из раннесарматского зеркала типа 4.7 (Скрипкин, 1990, с. 95; рис. $35,12)$. Зеркала данного типа появляются в III в. до н. э. и превалируют в комплексах II-I вв. до н. э. (Скрипкин, 1990, с. 151). В погребении также встречена восьмерковидная бронзовая пряжка, железный колчанный крючок и шесть бронзовых наконечников стрел (рис. 5: 3-6). Восьмерковидные пряжки А.С. Скрипкиным включены в группу вещей III-I вВ. до н. э. (Скрипкин, 1990, рис. 49). Подобные пряжки происходят из двух сарматских комплексов лесостепного Предуралья (Старые Киишки, к. XX, п. 7; Ново-Калкашево, к. 2, п. 5) (Садыкова, 1962, табл. ХІІ, 4; Акбулатов, 1998, рис. 5, 3). В обоих случаях пряжки найдены в комплексе с железными наконечниками стрел, то есть относятся ко времени не ранее II в. до н. э. В последнем случае встречена также прямоугольная ажурная пряжка с изображением лежащего верблюда (Акбулатов, 1998, рис. $5,2)$. Данные пряжки имеют среднеазиатское происхождение и датируются периодом сер. II-I вв. до н. э. (Скрипкин, 2000, с. 141-143). Автором раскопок Кипчаковского КГМ отмечается значительное количество восьмерковидных пряжек в ранней части некрополя, что позволило ему отнести данный тип к категории хроноиндикаторов II-I вв. до н. э. (Зубов, 2007, с. 90; Зубов, 2010, с. 72). Таким образом, эту группу пьяноборских погребений с ножнами рассматриваемого типа можно датировать в пределах II-I вв. до н. э.

Ножны данного типа представлены и в более поздних пьяноборских комплексах. В погребении 2 могильника Камышлы-Тамак (Илишевский район, Башкортостан) в качестве украшения устья ножен использована круглая ажурная бляха (рис. 5: 13). Возле нее фиксировались остатки деревянных планок, что предполагает присутствие деревянных деталей в ножнах. У конца клинка - 15 бронзовых пронизок и пряжка: остатки ремня, с помощью которого ножны крепились к бедру. Здесь же встречен железный наконечник стрелы (рис. 5: 15). В погребении 23 этого же могильника совместно с кинжалом среднесарматского облика встречена умбоновидная «воинская» бляха, расположенная у конца ножен (рис. 5: 16-18). Подобная умбоновидная бляха найде- 
на на среднесарматском кинжале в погребении 85 Юлдашевского могильника (Илишевский район, Башкортостан) (Пшеничнюк, 1986a, с. 65-66). Эти погребения отражают дальнейшее применение ножен с бляхами в среднесарматский период. Здесь мы наблюдаем замену однолезвийного клинка импортными экземплярами: двулезвийными кинжалами с кольцевым навершием. Также происходят некие конструктивные изменения в ножнах бляха остается одна. Эту группу погребений можно датировать рубежом эр.

В позднепьяноборское время использование ножен с бляхами практически не прослеживается. Бляхи продолжают использоваться спорадически в сочетании с другими деталями (например, металлическими наконечниками ножен), как это прослеживается в погребении 234 Ново-сасыкульского могильника (Илишевский район, Башкортостан) (Васюткин, Калинин, 1986, рис. 15, 24), либо в единственном экземпляре, как в погребении 446 Тарасовского могильника (Сарапульский район, Удмуртия). Здесь у конца длинного меча найдена круглая бляха (диаметр 5,5 см) с отверстием в центре (Голдина, 2003, рис. 193, 13).

Более широкое распространение данный тип ножен получает в андреевско-писеральских древностях. В Андреевском кургане (Большеигнатовский район, Мордовия) центральный костяк коллективного погребения 25 сопровождался кинжалом среднесарматского типа в ножнах, украшенных пятью бляхами и имеющих застежку-ворворку на конце ножен (Гришаков, Зубов, 2009, рис. 11a, $1 ; 21,1,6 ; 26,5,7)$. Слева от костяка лежал длинный однолезвийный клинок (палаш), от ножен которого сохранился металлический наконечник и бляха с 4-мя петельками, располагавшаяся у последней трети клинка (Гришаков, Зубов, 2009, рис. 21, 8; 26, 4, 9-10). Это погребение авторами публикации датируется I в. н. э. (Гришаков, Зубов, 2009, c. 45). В погребении 50 этого же некрополя захоронение воина сопровождалось палашом, от ножен которого остались 38 полушарных бляшек, украшавших их край, и крупная железная бляха, располагавшаяся в последней трети клинка (Гришаков, Зубов, 2009, рис. 12; $21,4)$. Комплекс этого погребения датируется третьей четвертью I в. н. э. (Гришаков, Зубов, 2009, с. 49).

Аналогичная картина наблюдается в воинском захоронении могильника Писералы
(Горно-Марийский район, Марий Эл). Здесь на правом бедре воина лежал кинжал, ножны которого были украшены 4 круглыми бляшками. Слева от погребенного был уложен меч, от ножен которого сохранилась крупная круглая бляха с отверстием в центре (Халиков, 1962, рис. 41; табл. XXIII, 1). Подобной бляхой были украшены также ножны меча из воинского комплекса Климкинских курганов (Горно-Марийский район, Марий Эл) (Архипов, Щадрин, 1995, рис. 10, 9). Хронологическая позиция этой группы памятников укладывается в пределах I-II вв. н. э. (Зубов, 2018, c. 14).

Таким образом, в конце раннесарматского периода (III-II вв. до н. э.) в памятниках предуральской лесостепи появляется тип ножен с бляхами, связанный с короткими (до 50 см) однолезвийными боевыми клинками. Первоначально он фиксируется в Шиповском КГМ, затем в раннепьяноборских комплексах II-I вв. до н. э., при этом в собственно кара-абызских древностях распространение данного типа ножен не прослеживается. В первых веках нашей эры применение ножен с бляхами в пьяноборской среде практически затухает. Зато памятники писеральско-андреевского круга I-II вв. н. э. демонстрируют расцвет и дальнейшее развитие данной традиции на примере статусных воинских комплексов, содержащих как короткие (кинжалы), так и длинные боевые клинки (палаши, мечи).

На наш взгляд, появление и распространение данного типа ножен в регионе УралоПоволжья связано с миграцией небольшой группы военизированного населения, связанного своим происхождением с лесостепными культурами Зауралья и Западной Сибири. Об этом нам приходилось уже писать при анализе погребального обряда курганной части Шиповского КГМ (Овсянников, 2018, с. 59-60). С этой миграционной волной связано появление в Шипово II-й и III-й групп курганов, а также Нагаевских и Акбердинских курганных групп и основание Акбердинского II городища с открытым недавно воинским святилищем (Овсянников, 2009, с. 145; Овсянников, Савельев, 2019).

Ранее С.Э. Зубовым указывалась связь исследованного им Кипчаковского I КГМ с Нагаевскими, Акбердинскими и Шиповскими курганами (Зубов, 2007a, с. 85). Со своей стороны, нам представляется, что Кипчаковский археологический комплекс в целом является одним из звеньев в цепи переселений 
внутри Урало-Поволжского региона, отправной точкой которых явилось лесостепное Зауралье, затем Среднее и Нижнее Прибелье, а конечной - Посурье, которую маркируют памятники писеральско-андреевского типа.

Таким образом, в рамках дискуссии о происхождении данного типа памятников (о самой дискуссии см.: Гришаков, Зубов, 2009, с. 70-88; Зубов, 2011, с. 87-112) может быть расширена доказательная база о присутствии зауральского компонента в памятниках Посурья первых веков нашей эры за счет привлечения материалов из ареала кара-абызской культуры.

\section{ЛИТЕРАТУРА}

Агеев Б.Б. Пьяноборская культура. Уфа: БНЦ УрО РАН, 1992. 140 с.

Акбулатов И.М. Ново-Калкашский II курганный могильник на р. Стерля // УАВ. Вып. 1. Уфа: ИИЯЛ УНЦ РАН, 1998. С. 121-137.

Архипов Г.А., Шадрин А.И. Исследование раннесредневековых курганов у с. Климкино // Новые материалы по археологии Среднего Поволжья / АЭМК. Вып. 24 / Науч. ред. В.В. Никитин. ЙошкарОла: МарНИИ, 1995. С. 110-129.

Васюткин С.М., Калинин В.К. Ново-Сасыкульский могильник // Археологические работы в низовьях Белой / Отв. ред. А.Х. Пшеничнюк. Уфа: БФАН СССР, 1986. С. 95-122.

Генинг В.Ф. История населения удмуртского Прикамья в пьяноборскую эпоху. Ч. II / Археологические памятники чегандинской культуры (ІІІ в. до н.э. - ІІ в. н.э.) / ВАУ. Вып. 11 / Отв. ред. В.А. Семенов. Свердловск-Ижевск, 1971. 159 с.

Голдина Р.Д. Тарасовский могильник I-V вв. на Средней Каме. Т. II. Ижевск: Удмуртия, 2003. 721 с.

Гришаков В.В., Зубов С.Э. Андреевский курган в системе археологических культур раннего железного века Восточной Европы / Археология евразийских степей. Вып. 7. Казань: Институт Истории им. Ш. Марджани АН РТ; Самарский муниципальный институт управления, 2009. 173 с.

Дмитриев П.А., Сальников К.В. Отчет Уфимской экспедиции ГАИМК с работ трассы Уфа-Ишимбаево в 1934 г. // Научный архив УФИЦ РАН, 1934.

Зубов С.Э. Кипчаковский культурно-хронологический горизонт в системе пьяноборской культуры // УАВ. Вып. 6-7. Уфа: Гилем, 2007. С. 72-88.

Зубов С.Э. Новые элементы погребальной обрядности раннепьяноборского населения в низовьях р. Белой (по материалам раскопок Кипчаковского курганно-грунтового могильника в 2006 году) // УАВ. Вып. 10. Уфа: Гилем, 2010. С. 64-82.

Зубов С.Э. Хроноиндикаторы раннепьяноборских могильников икско-бельского междуречья // Проблемы археологии Нижнего Поволжья. II Междунар. Нижневолж. Археол. Конф., г. Волгоград, 12-15 нояб. 2007 г.: тез. докл. / Отв. ред. А. В. Кияшко, А. С. Скрипкин. Волгоград: Изд-во ВолГУ, 2007. C. $87-96$.

Зубов С.Э. Воинские миграции римского времени в Среднем Поволжье (I-III вв.). Миграционные процессы в формировании новой этнокультурной среды по материалам археологических данных. Saarbrucken: Lap Lambert Academic Publishing, 2011. 201 c.

Зубов С.Э. История изучения памятников писеральско-андреевского типа // Археология Евразийских степей. 2018. № 1. С. 9-16.

Зубов С.Э., Саттаров Р.Р. Наконечники стрел пьяноборской культуры как хронологические маркеры (по материалам погребальных комплексов Кипчаковского I курганно-грунтового могильника) // XXI Уральское археологическое совещание, посвященное 85 -летию со дня рождения Г.И. Матвееевой и 70-летию со дня рождения И.Б. Васильева. Материалы Всероссийской научной конференции с международным участием. 8-11 октября 2018 г. / Отв. ред. А.А. Выборнов. Самара: Изд-во СГСПУ, ООО «Порто-Принт», 2018. С. 210-214.

Иванов В.А. О времени функционирования могильников эпохи раннего железа в Приуралье // Древности Среднего Поволжья / Отв. ред. Г.И. Матвеева. Куйбышев: Куйбышевский гос. университет, 1985. C. 85-99.

Клепиков B.М., Скрипкин А.С. Хронология раннесарматских памятников Нижнего Поволжья // НАВ. Вып. 5. / Отв. ред. А.С. Скрипкин, В.М. Клепиков. Волгоград: Изд-во Волгоград. Гос. университета, 2002. С. 47-81.

Мажитов Н.А., Пшеничнюк А.Х. Камышлы-Тамакский могильник // АЭБ. Т. ІІІ / Отв. ред. Р.Г. Кузеев. Уфа: БФ АН СССР, 1968. С. 38-58. 
Овсянников В.В. Опыт выделения зон активного взаимодействия оседлого и кочевого населения Предуралья в савромато-сарматскую эпоху // УАВ. Вып. 9. Уфа: Гилем, 2009. С. 144-156.

Овсянников B.B. Общие элементы в погребальном обряде и инвентаре населения кара-абызской культуры и сармат лесостепи Южного Предуралья (по материалам Шиповских, Старо-Киишкинских и Бишунгаровских курганов) // Сарматы и внешний мир. Материалы VIII Всероссийской (с международным участием) научной конференции «Проблемы сарматской археологии и истории» (Уфа, ИИЯЛ УНЦ РАН, 12-15 мая 2014 г.) / Отв. ред. Л.Т. Яблонский, Н.С. Савельев (УАВ. Вып. 14). Уфа: ИИЯЛ УНЦ РАН, Центр «Наследие», 2014. С. 168-177.

Овсянников В.B. Новые материалы Шиповского курганно-грунтового могильника в лесостепном Предуралье // УАВ. Вып. 18. Уфа: Гилем, 2018. С. 43-62.

Овсянников В.В., Савельев Н.С. Воинское святилище на Акбердинском II городище // Археология Евразийских степей. 2019. № 2. С. 201-226.

Пшеничнюк A.X. Памятники ананьинской и пьяноборской культур в низовьях р. Белой // Археологические работы в низовьях Белой / Отв. ред. А.Х. Пшеничнюк. Уфа: БФАН СССР, 1986. С. $26-44$.

Пшеничнюк А.X. Юлдашевский могильник // Археологические работы в низовьях Белой / Отв. ред. А.Х. Пшеничнюк. Уфа: БФАН СССР, 1986а. С. 45-74.

Садықкова М.X. Сарматский курганный могильник у дер. Старые Киишки // АЭБ. Т. I О Отв. ред. Р.Г. Кузеев, К.В. Сальников. Уфа: БФАН СССР, 1962, С. 88-122.

Скрипкин А.С. Азиатская Сарматия. Проблемы хронологии и ее исторический аспект. Саратов: Изд-во Саратовского ун-та, 1990. 300 с.

Скрипкин А.C. К проблеме выделения сарматских памятников азиатской Сарматии II-I вв. до н.э. // Раннесарматская культура: формирование, развитие, хронология. Материалы IV международной конференции «Проблемы сарматской археологии и истории». Вып. 1. / Отв.ред. В.Н. Мышкин. Самара: Изд-во СНЦ РАН, 2000. С. 137-149.

Степная полоса Азиатской части СССР в скифо-сарматское время. Археология СССР / Отв. ред. М.Г. Мошкова. М.: Наука, 1992. 494 с.

Халиков А.X. Очерки истории населения Марийского края в эпоху железа // Железный век Марийского края / Тр. МАЭ. Т. ІІ / Отв. ред. Г.А. Архипов. Йошкар-Ола: Марийское книж. изд-во, 1962. C. $7-187$.

Шульга П.И. О назначении «поясных» бляшек на верхней Оби и в горном Алтае // Древние и средневековые кочевники Центральной Азии / Отв. ред. А.А. Тишкин. Барнаул: Азбука, 2008. С. 116-119.

\section{Информация об авторе:}

Овсянников Владимир Владиславович, кандидат исторических наук, заведующий отделом археологических исследований Института истории, языка и литературы Уфимского научного центра Российской академии наук; atliural@yandex.ru

\section{REFERENCES}

Ageev, B. B. 1992. P'ianoborskaia kul 'tura (The Pyany Bor Culture). Ufa: Bashkir Research Center, Ural Branch of the Russian Academy of Sciences (in Russian).

Akbulatov, I. M. 1998. In Ufimskii arkheologicheskii vestnik (Ufa Archaeological Herald) 1. 121-137 (in Russian).

Arkhipov, G. A., Shadrin, A. I. 1995. In Nikitin, V. V. (ed.). Novye materialy po arkheologii Srednego Povolzh'ia (New Materials on the Archaeology of the Middle Volga Region). Arkheologiia i etnografiia Mariiskogo kraia (Archaeology and Ethnography of the Mari Land) 24. Yoshkar-Ola: Mari Research Institute of Language, Literature, History and Ethnography Institute 110-129 (in Russian).

Vasyutkin, S. M., Kalinin, V. K. 1986. In Pshenichniuk, A. Kh. (ed.). Arkheologicheskie raboty vnizov'iakh Beloi (Archaeological Investigations in the Lower Belaya Area). Ufa: Bashkirian Branch of the USSR Academy of Sciences, 95-122 (in Russian).

Gening, V. F. 1971. Istoriia naseleniia Udmurtskogo Prikam'ia v p'ianoborskuiu epokhu. Ch. II. Arkheologicheskie pamiatniki chegandinskoi kul'tury (III v. do n.e. - II v. n.e.) (History of Udmurt Kama Population in the Pyany Bor epoch. Part II. Cheganda Culture Archaeological Sites (3rd Century BC 2nd Century AD)) In Semenov, V. A. (ed.). Voprosy arkheologii Urala (Issues of the Ural Archaeology) 11. Sverdlovsk; Izhevsk (in Russian).

Goldina, R. D. 2003. Tarasovskii mogil'nik I-Vvv. na Srednei Kame (Tarasovo Burial Ground of 1st-5th Centuries in the Middle Kama Region) II. Izhevsk: "Udmurtiia" Publ. (in Russian). 
Grishakov, V. V., Zubov, S. E. 2009. Andreevskii kurgan v sisteme arkheologicheskikh kul'tur rannego zheleznogo veka Vostochnoi Evropy (Andreevka Burial Mound in the System of the Early Iron Age Archaeological Cultures of Eastern Europe). Series: Arkheologiia evraziiskikh stepei (Archaeology of the Eurasian Steppes) 7. Kazan: Institute of History named after Shigabuddin Mardzhani, Tatarstan Academy of Sciences; Samara Municipal Institute for Public Administration (in Russian).

Dmitriev, A. V., Sal'nikov, K. V. 1934. Otchet Ufimskoi ekspeditsii Gosudarstvennoi Akademii istorii material'noi kul'tury s rabot trassy Ufa-Ishimbaevo v 1934 g. (Report of the Ufa Expedition of the State Academy for the History of Material Culture about the Activity of the Ufa-Ishimbaevo Route in 1934). Scientific Archive of the Ufa Scientific Center, Russian Academy of Sciences (in Russian).

Zubov, S. E. 2007. In Ufimskii arkheologicheskii vestnik (Ufa Archaeological Herald) 6-7. Ufa: "Gilem" Publ., 72-88 (in Russian).

Zubov, S. E. 2007. In Kiyashko, A. V., Skripkin, A. S. (eds.). Problemy arkheologii Nizhnego Polozh'ia (Issue of the Archaeology of the Lower Volga Region) Volgograd: Volgograd State University, 87-96 (in Russian).

Zubov, S. E. 2010. In Ufimskii arkheologicheskii vestnik (Ufa Archaeological Bulletin) 10. Ufa: "Gilem" Publ., 64-82 (in Russian).

Zubov, S. E. 2011. Voinskie migratsii rimskogo vremeni v Srednem Povolzh'e (I-III vv.). Migratsionnye protsessy $v$ formirovanii novoi etnokul'turnoi sredy po materialam arkheologicheskikh dannykh (Warriors Migrations of the Roman Time in the Middle Volga Area (1st-3rd Centuries). Migrational Processes in the New Ethnic and Cultural Environment, by the Archaeological Data). Saarbrucken: Lap Lambert Academic Publishing (in Russian).

Zubov, S. E. 2018. In Arkheologiia Evraziiskikh stepei (Archaeology of Eurasian Steppes) 1, . 9-16 (in Russian).

Zubov, S. E., Sattarov, R. R. 2018. In Vybornov, A. A. (ed.). XXI Ural'skoe arkheologicheskoe soveshchanie (21th Urals Archaeological Congress)). Samara: "Samara State University of Social Sciences and Education", "Porto-Print" Publ., 210-214 (in Russian).

Ivaniv, V. A.1985. In Matveeva, G. I. (ed.). Drevnosti Srednego Povolzh'ia (Antiquities of the Middle Volga Area). Kuybyshev: Kuybyshev State University, 85-99 (in Russian).

Klepikov, V. M., Skripkin, A. S. 2002. In Skripkin, A. S., Klepikov, V. M. (eds.). Nizhnevolzhskii arkheologicheskii vestnik (Lower Volga Archaeological Bulletin) 5. Volgograd: Volgograd State University, 47-81 (in Russian).

Mazhitov, N. A., Pshenichniuk, A. Kh. 1968. In Kuzeev, R. G. (ed.). Arkheologiia i etnografiia Bashkirii (Archaeology and Ethnography of Bashkiria) III. Ufa: Bashkirian Branch of the USSR Academy of Sciences, 38-58 (in Russian).

Ovsyannikov, V. V., 2009. In Ufimskii arkheologicheskii vestnik (Ufa Archaeological Herald) 9. Ufa: "Gilem" Publ., 144-156 (in Russian).

Ovsyannikov, V. V., 2014. In Yablonsky, L. T., Savelyev, N. S. (eds.). Sarmaty i vneshnii mir (Sarmatians and the External World). Series: Ufimskii arkheologicheskii vestnik (Ufa Archaeological Herald) 14. Ufa: Russian Academy of Sciences, Urals Scientific Center, Institute for History, Language, and Literature; "Nasledie" Publ., 168-177 (in Russian).

Ovsyannikov, V. V., 2018. In Ufimskii arkheologicheskii vestnik (Ufa Archaeological Herald) 18. Ufa: "Gilem" Publ., 43-62 (in Russian).

Ovsyannikov, V. V., Savel'ev, N. S. 2019. In Arkheologiia Evraziiskikh stepei (Archaeology of Eurasian Steppes) 2, 201-226 (in Russian).

Vasyutkin, S. M., Kalinin, V. K. 1986. In Pshenichniuk, A. Kh. (ed.). Arkheologicheskie raboty v nizov'iakh Beloi (Archaeological Investigations in the Lower Belaya Area). Ufa: Bashkirian Branch of the USSR Academy of Sciences, 26-44 (in Russian).

Pshenichniuk, A. Kh. 1986. In Pshenichniuk, A. Kh. (ed.). Arkheologicheskie raboty v nizov'iakh Beloi (Archaeological Investigations in the Lower Belaya Area). Ufa: Bashkirian Branch of the USSR Academy of Sciences, 45-74 (in Russian).

Sadykova, M. Kh. 1962. In Kuzeev, R. G., Sal'nikov, (ed.). Arkheologiia i etnografiia Bashkirii (Archaeology and Ethnography of Bashkiria) I. Ufa: Bashkir Branch of the USSR Academy of Sciences, 88-122 (in Russian).

Skripkin, A. S. 1990. Aziatskaia Sarmatiia (problemy khronologii i ee istoricheskii aspekt) (Sarmatia Asiatica: Issues of Chronology and Its Historical Aspect). Saratov: Saratov University (in Russian). 
Skripkin, A. S. 2000. In Myshkin, V. N. (ed.). Rannesarmatskaia kul'tura: formirovanie, razvitie, khronologiia (Early Sarmatian Culture: Formation, Development, Chronology) Samara: Institute of Archaeology, Russian Academy of Sciences, 137-149 (in Russian).

Moshkova, M. G. (ed.). 1992. Stepnaia polosa Aziatskoi chasti SSSR v skifo-sarmatskoe vremia (The Steppe Belt of the Asian Part of USSR in the Scythian and Sarmatian Time). Series: Archaeology of the USSR 12. Moscow: "Nauka" Publ. (in Russian).

Khalikov, A. Kh. 1962. In Arkhipov, G. A. (ed.). Zheleznyi vek Mariiskogo kraia (Iron Age of the Mari Region). Series: Proceedings of the Mari Archaeological Expedition II. Yoshkar-Ola: "Mariiskoe knizhnoe izdatel'stvo" Publ., 7-187 (in Russian).

Shul'ga, P. I. 2008. In Tishkin, A. A. (ed.). Drevnie i srednevekovye kochevniki Tsentral'noi Azii (Antique and Medieval Nomads of Central Asia). Barnaul: "Azbuka” Publ., 216-220 (in Russian).

\section{About the Author:}

Ovsyannikov Vladimir V., Candidate of historical sciences, Institute of history, language and literature of the Ufa scientific center of the Russian Academy of Sciences. Octyabrya av., 71, Ufa, 450054, the Republic of Bashkortostan, Russia Federation; atliural@yandex.ru

Статья поступила в журнал 01.08.2020 г. Статья принята к публикации 01.09.2020 г. 


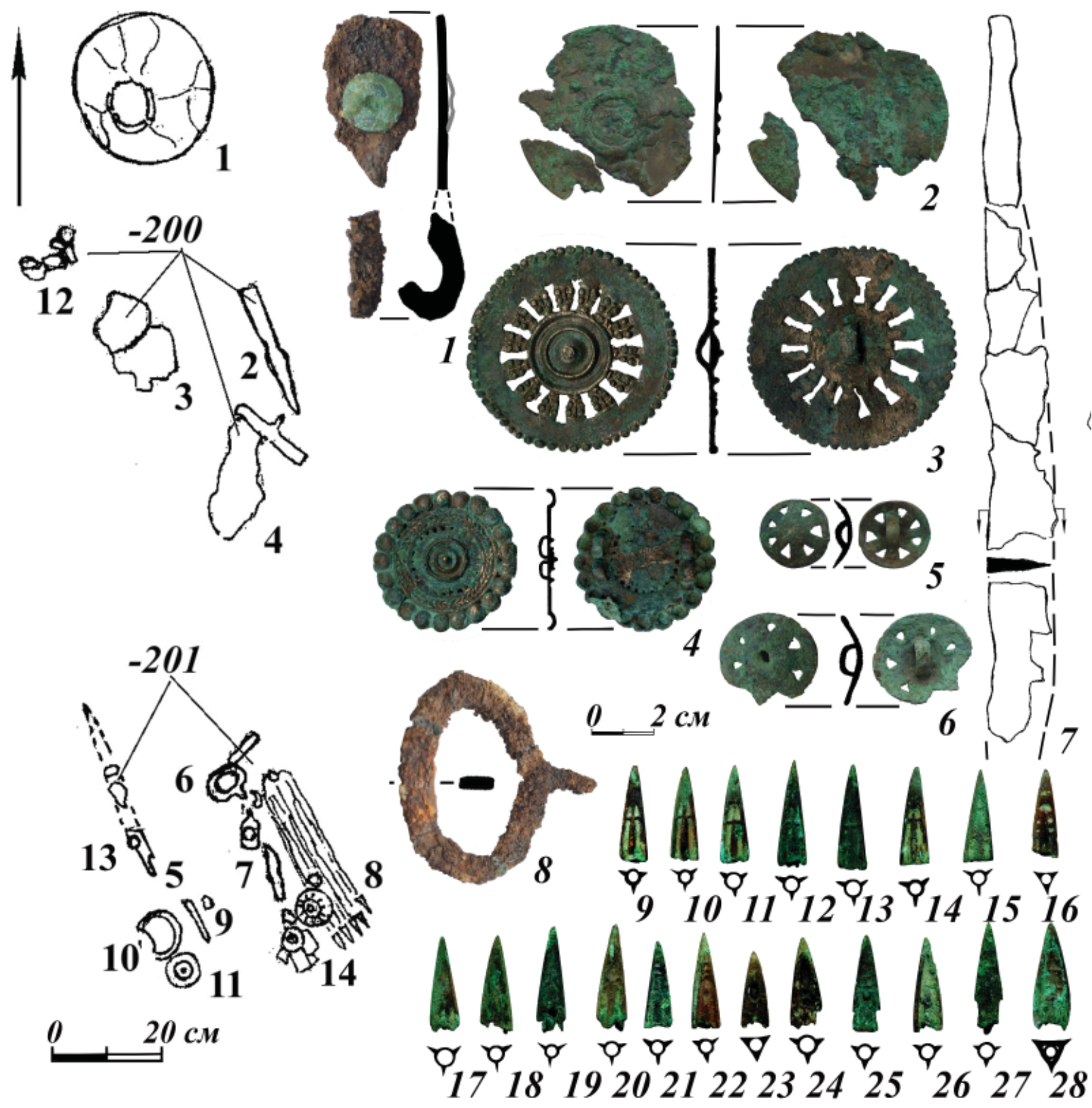

Рис. 1. Первый комплекс из кургана 2, III группы Шиповского курганно-грунтового могильника.

Fig. 1. The first complex from barrow 2, group III of the Shipovo barrow subsoil burial ground. 

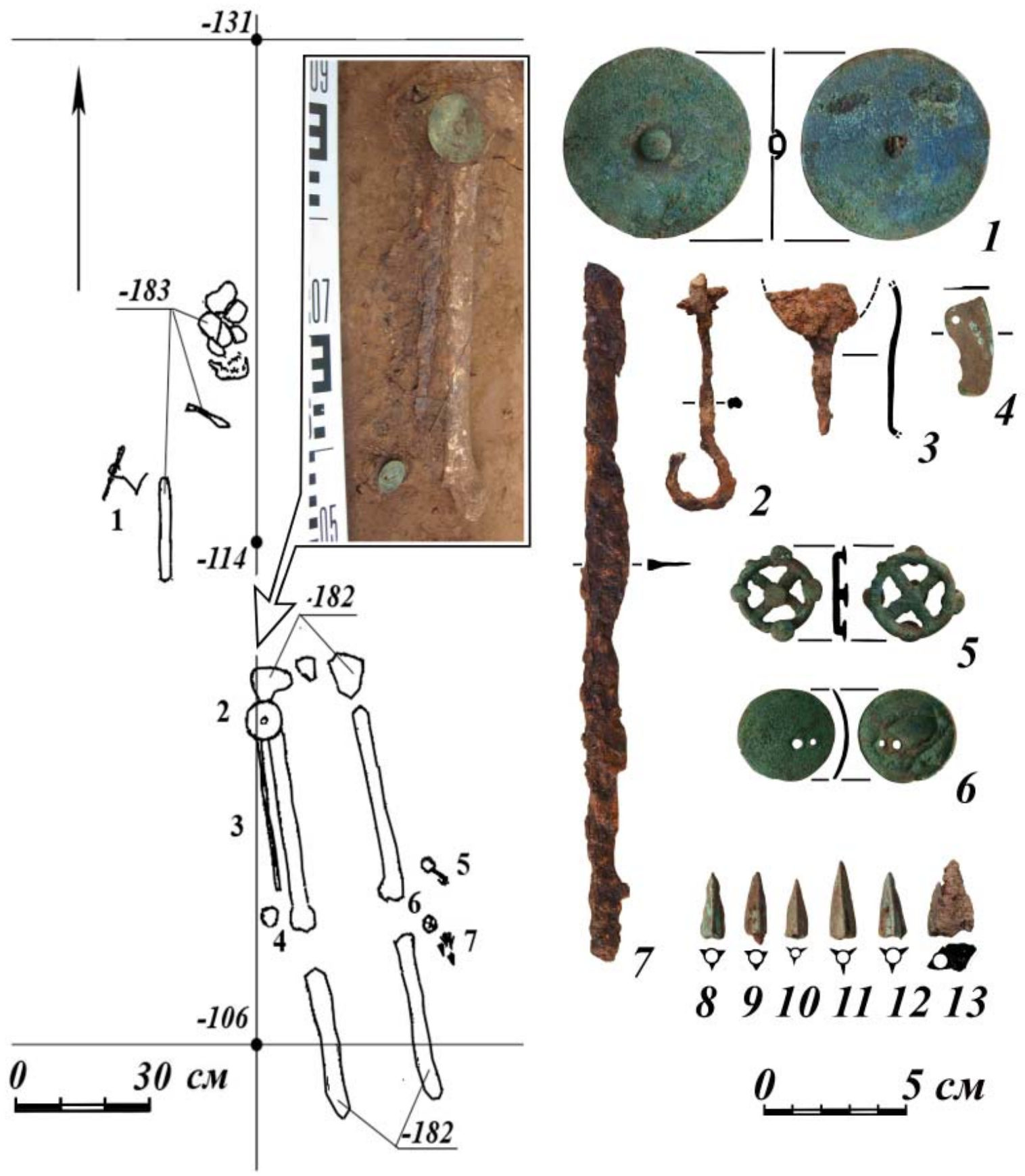

Рис. 2. Материал из впускного погребения кургана 24, II группы курганов Шиповского курганно-грунтового могильника.

Fig. 2. Material from the inlet burial of barrow 24, group II of the barrows of the Shipovo barrow subsoil burial ground 

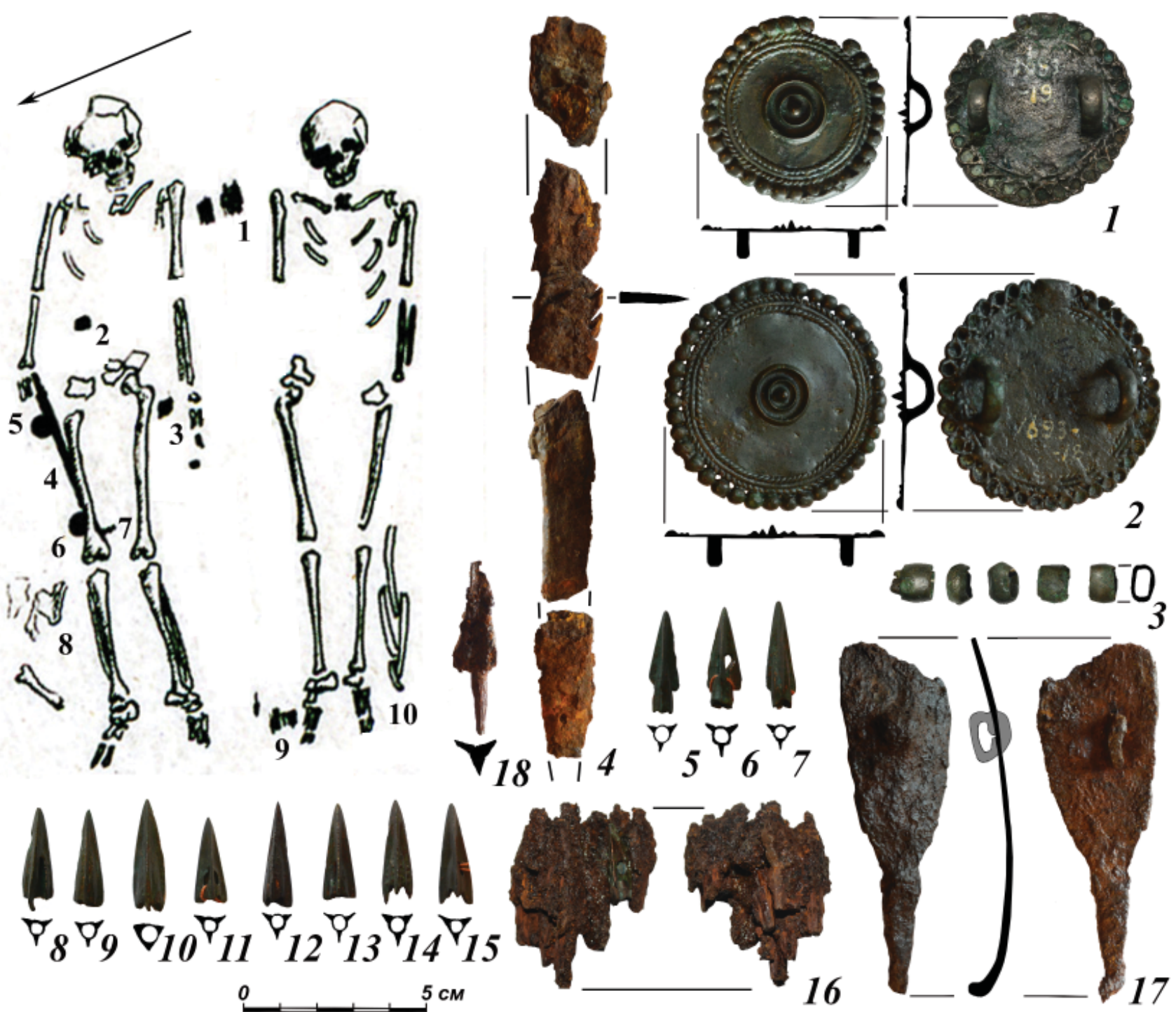

Рис. 3. Воинский комплекс из кургана IX Старо-Киишкинского курганного могильника (раскопоки 1934 г.). Fig. 3. Military complex from barrow IX of the Starye Kiishki burial mound (excavations of 1934) 

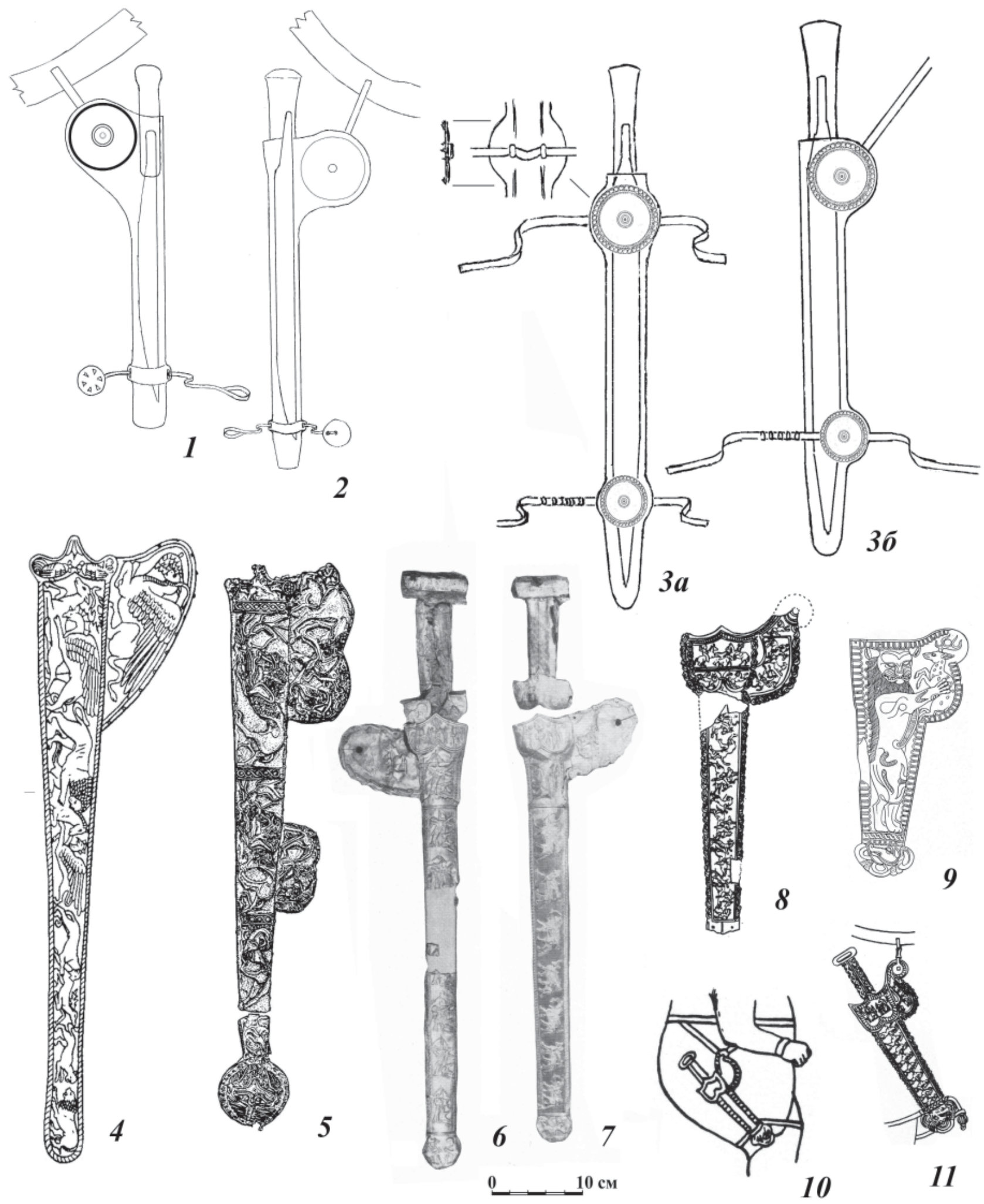

Рис. 4. Реконструкция крепления ножен акинака к поясу с помощью крупных круглых блях и их скифо-бактрийские аналогии.

Fig. 4. Reconstruction of the attachment of an acinaces sheath to the belt using large round plates and their Scytho-Bactrian counterparts 

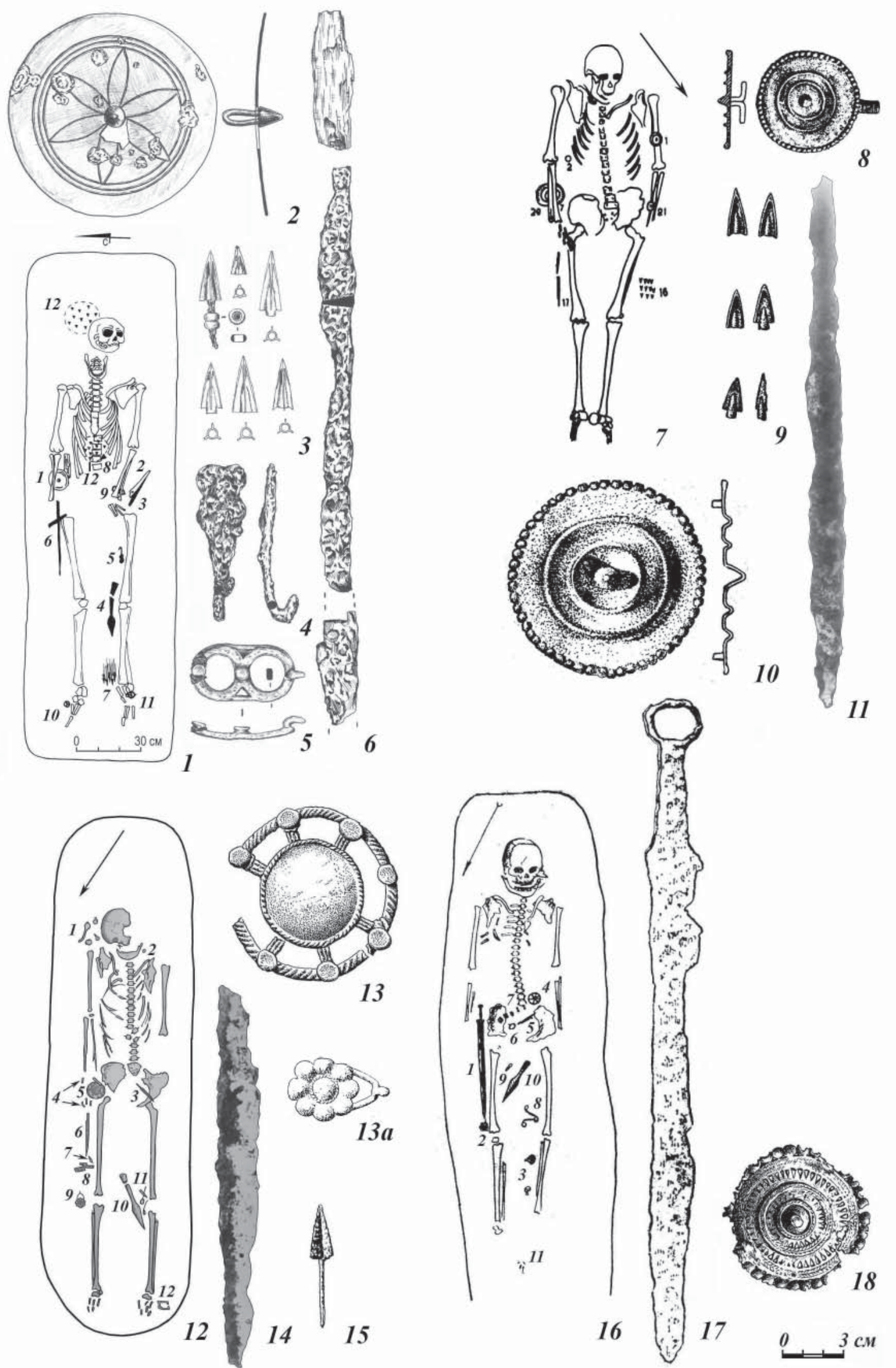

Рис. 5. Ножны мечей из поздних пьяноборских комплексов.

Fig. 5. Sword sheaths from the late Pyany Bor complexes. 